\title{
Dry grinding of talc in a stirred ball mill
}

\author{
Serkan Cayirli, ${ }^{1, a}$ \\ ${ }^{1}$ Nigde University, Department of Mining Engineering, 51240 Central Campus, Turkey
}

\begin{abstract}
The aim of this work was to investigate micro fine size dry grindability of talc in a stirred ball mill. The effects of various parameters such as grinding time, stirrer speed, powder filling ratio and ball filling ratio were investigated. Alumina balls were used as grinding media. Experiments were carried out using the $2^{4}$ full factorial design. The main and interaction effects were evaluated using the Yates method. Test results were evaluated on the basis of product size and surface area.
\end{abstract}

\section{Introduction}

Talc, the softest of all minerals with a Mohs hardness of 1 , is an organophilic, water repellent and chemically inert mineral. It is characterized as a hydrated magnesium sheet silicate with the formula $\mathrm{Mg}_{3} \mathrm{Si}_{4} \mathrm{O}_{10}(\mathrm{OH})_{2}$. Talc is a functional component (filler) in paper, paints, plastics, rubbers, ceramics, fertilizers, animal feed, cosmetics, pharmaceuticals and other applications [1]. Size specifications for talc are of considerable importance, depending primarily on the particular end purpose, and to a great extent, on the physical properties of the mineral itself [2]. It is therefore pertinent to improve the basic properties of industrial minerals by the grinding method employed. Generally, milling of these minerals can be performed in the conventional tumbling, impact, stirred ball, jet and vibration mills. However, in the fine size range, the economic and process considerations show the last three milling methods to be the most versatile, depending on the product and use [3]. Due to higher power density (density of the energy absorbed by the particles) and better grinding efficiency, high-speed stirred ball mills are considered as an interesting alternative to conventional tumbling mills and vibratory mills for fine grinding and delamination processes in the minerals industry [4-6].

The aim of this study is to determine the operating conditions for the dry grinding of talc to micro fine sizes using a laboratory vertical stirred ball mill.

\section{Material and method}

\subsection{Material}

A talc sample $\left(S_{v}=1.57 \mathrm{~m}^{2} / \mathrm{cm}^{3}\right)$ used in the grinding experiments obtained from Mikron'S Company, Nigde, Turkey. The chemical analysis (by X-rayfluorescence) of the sample is given in Table 1.The

\footnotetext{
${ }^{a}$ Corresponding author: scayirli@nigde.edu.tr
} 
specific density of talc is $2.78 \mathrm{~g} / \mathrm{cm}^{3}$. The typical size distribution of the feed sample is presented in Figure 1. Alumina balls with diameters $2.5-3.5 \mathrm{~mm}$ mixtures $\left(33 \%\right.$ of each) a density of $3.6 \mathrm{~g} / \mathrm{cm}^{3}$ were used as the grinding media.

Table 1. Chemical analysis of the sample.

\begin{tabular}{ccccc}
\hline $\mathrm{SiO}_{\mathbf{2}}$ & $\mathrm{MgO}$ & $\mathbf{C a O}$ & $\mathrm{Fe}_{\mathbf{2}} \mathbf{O}_{\mathbf{3}}$ & $\mathrm{Al}_{\mathbf{2}} \mathbf{O}_{\mathbf{3}}$ \\
$\mathbf{( \% )}$ & $(\mathbf{\%})$ & $\mathbf{( \% )}$ & $(\%)$ & 0.003 \\
\hline 63.15 & 33.33 & 0.79 & 3.12 & 0.003 \\
\hline
\end{tabular}

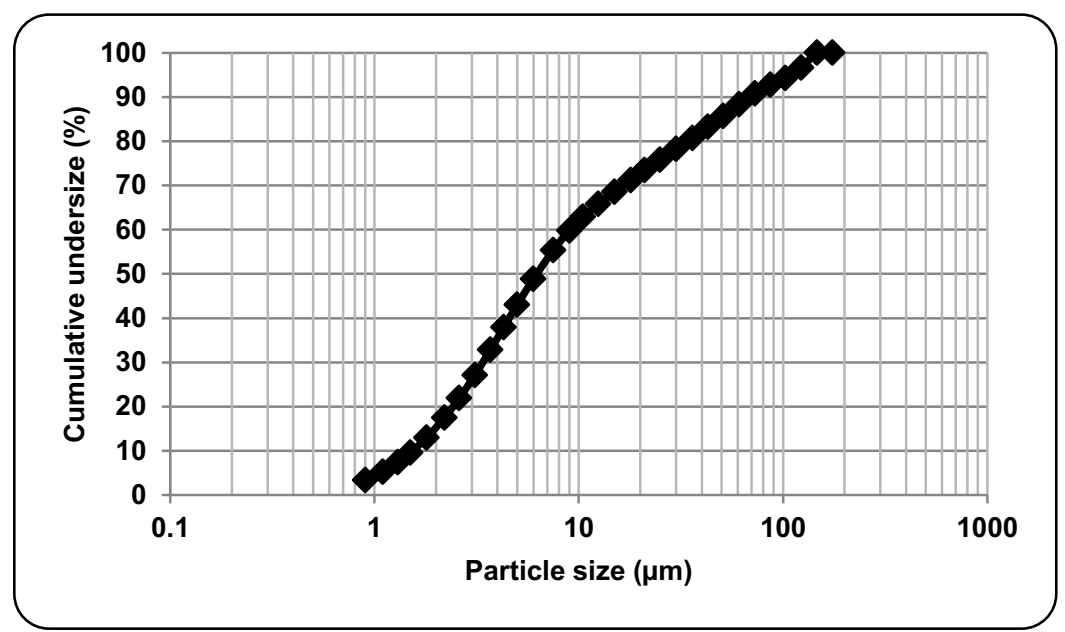

Figure 1. Particle size distribution of a feed sample.

\subsection{Method}

The grinding tests were performed in a stirred ball mill Standart-01 Model manufactured by Union Process (Fig. 2). It comprises a $595 \mathrm{ml}$ cylindrical alumina (99.9\%) grinding tank. The stirrer axis is fitted with four slotted stainless steel shaft and arms. For cooling purposes, the grinding chamber is also equipped with a water jacket for cooling. The shaft run at 100-600 rpm and can be used for either wet or dry grinding.

The grinding tests were carried out as a batch process in which samples were taken from the pot at the determined grinding time intervals. After each test, all of the media and ground samples were removed from the mill and the media were separated from the products by sieving. A series of experiments were carried out to investigate the effects of experimental parameters such as the grinding time, stirrer speed, powder filling ratio and ball filling ratio $(J)$ on the particle size distribution (PSD) and surface area $\left(S_{v}\right)$ of the products. A Sympatec HELOS (H1613) laser sizer was used for analysis of the feed and the ground products. Each test was repeated three times and the values reported are a mean average.

The primary aim of this study was to determine the optimum grinding conditions for producing the maximum surface area. The surface area is one of the basic properties of the powder and is generally represented by the total surface area of all particles contained in a unit mass of the powder [7]. The success of fine grinding depends on the selection of suitable parameters, and optimization of these parameters necessitates many tests. The total number of required experiments can be reduced by employing a factorially designed series, using the Yates technique [8]. 


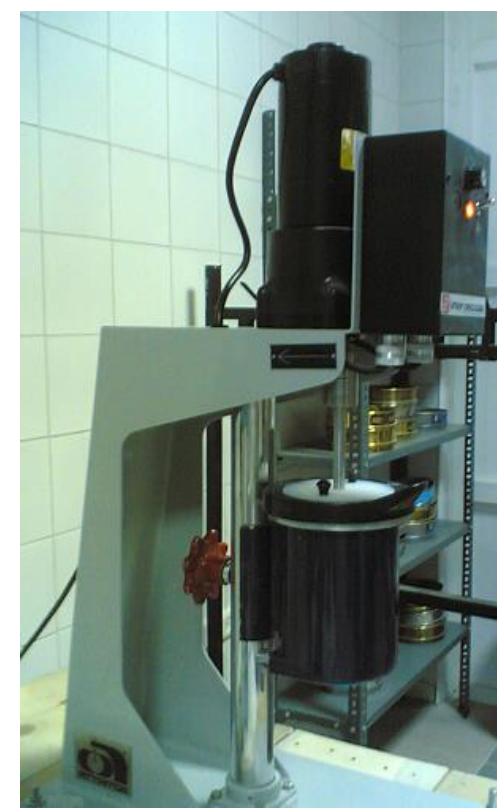

Figure 2. A stirred ball mill used in grinding tests.

Within these studies, the main and interaction effects of four variables on fine grinding were investigated. All $2^{4}$ full factorial unreplicated experiments were carried out to evaluate the main and interaction effects of each variable in talc grinding. The Yates notation was used in this work to name each treatment. For example, treatment $a b c d$ was the experimental run in which the variables $a$ (grinding time), $b$ (stirrer speed), $c$ (powder filling ratio), and $d$ (ball filling ratio) were set to their high level. The factorial design of an experiment requires a series of parameter combinations in which all possibilities are considered by the variation of parameters. The number of experiments required is given by the equation $N=2^{n}$. In this equation, $N$ denotes the number of experiments and $n$ is the number of parameters. The number of parameters in this case is 4 , corresponding to a total of 16 experiments. The parameters and the levels of each of the $2^{4}$ designs, along with the actual and coded values of the parameters of the experiments, are presented in Table 2. The higher and lower levels are assigned +1 and -1 values, respectively, and zero represents the base level.

Table 2. Parameter codes and parameters values at different levels for experimental modelling.

\begin{tabular}{lccccc}
\hline Variables & $\begin{array}{c}\text { Parameter } \\
\text { code }\end{array}$ & $\begin{array}{c}\text { Yates } \\
\text { Symbol }\end{array}$ & $\begin{array}{c}\text { Lower level } \\
(-\mathbf{1})\end{array}$ & $\begin{array}{c}\text { Base level } \\
(\mathbf{0})\end{array}$ & $\begin{array}{c}\text { Higher level } \\
(+\mathbf{1})\end{array}$ \\
\hline Grinding time $(\mathrm{min})$. & $\mathrm{X}_{1}$ & $a$ & 5 & 10 & 15 \\
Stirrer speed $(\mathrm{rpm})$ & $\mathrm{X}_{2}$ & $b$ & 300 & 450 & 600 \\
Powder filling ratio $\left(f c^{*}\right)$ & $\mathrm{X}_{3}$ & $c$ & 0.03 & 0.05 & 0.07 \\
Ball filling ratio $\left(J^{*}\right)$ & $\mathrm{X}_{4}$ & $d$ & 0.50 & 0.60 & 0.70 \\
\hline
\end{tabular}

$$
\begin{gathered}
f c=\frac{\frac{\text { mass of powder }}{\text { powder density }}}{\text { mill volume }} \cdot \frac{1.0}{0.6} \\
J=\frac{\text { mass of balls } / \text { ball density }}{\text { mill volume }} \times \frac{1.0}{0.6} .
\end{gathered}
$$


According to the basic principles of experimental design, three experiments were carried out at the base level, designated 0 , to estimate the error and standard deviation. The tests are listed in Table 3 along with the alternative levels that were used in the experiments.

Table 3. Factor levels for each set of process variables.

\begin{tabular}{lccccc}
\hline & \multicolumn{2}{c}{ Factor levels } & Experimental results \\
Exp. no & $a$ & $b$ & $c$ & $d$ & $\boldsymbol{S}_{\boldsymbol{v}}\left(\mathbf{m}^{2} / \mathbf{c m}^{\mathbf{3}}\right)$ \\
\hline 1 & -1 & -1 & -1 & -1 & 2.14 \\
2 & +1 & -1 & -1 & -1 & 2.62 \\
3 & -1 & +1 & -1 & -1 & 2.27 \\
4 & +1 & +1 & -1 & -1 & 2.98 \\
5 & -1 & -1 & +1 & -1 & 2.01 \\
6 & +1 & -1 & +1 & -1 & 2.28 \\
7 & -1 & +1 & +1 & -1 & 2.06 \\
8 & +1 & +1 & +1 & -1 & 2.48 \\
9 & -1 & -1 & -1 & +1 & 2.28 \\
10 & +1 & -1 & -1 & +1 & 2.89 \\
11 & -1 & +1 & -1 & +1 & 2.50 \\
12 & +1 & +1 & -1 & +1 & 3.34 \\
13 & -1 & -1 & +1 & +1 & 2.13 \\
14 & +1 & -1 & +1 & +1 & 2.53 \\
15 & -1 & +1 & +1 & +1 & 2.22 \\
16 & +1 & +1 & +1 & +1 & 2.82 \\
BLR & 0 & 0 & 0 & 0 & 2.47 \\
BLR & 0 & 0 & 0 & 0 & 2.47 \\
BLR & 0 & 0 & 0 & 0 & 2.50 \\
\hline
\end{tabular}

\section{Results and discussion}

Within the study, the main and interaction effects of four parameters such as the grinding time, stirrer speed, powder filling ratio and ball filling ratio $(J)$ on the specific surface area $\left(S_{v}\right)$ of the ground product were investigated. In other words, the main goal was to determine the optimal set of variables that could be used in grinding to obtain the maximum surface area.

The Yates technique for the $2^{4}$ experiments (where four is the number of parameters) was used for the statistical design and analysis of the results. The experimental conditions were arranged in the socalled Yates order. Table 4 combines the Yates technique with the analysis of variance method (ANOVA) to simplify the decision-making process on the significance of the parameters investigated.

The procedure for preparing Table 4 is as follows $[9,10]$.

1. The upper half of column 3 is obtained by adding successive pair responses, and the lower half is obtained by subtracting successive pairs. Columns 4,5 , and 6 are calculated in the same way.

2. Tests are repeated three times at the center points to estimate the error associated with determination of an individual response, which is required to test the statistical significance.

3. The ANOVA procedure is applied.

4. The table value of $F(1.16)$ for $\alpha=0.05$ is compared with the calculated $F$ value.

5. If $F_{\text {Calculated }}>F_{\text {Table }}$, then decision is effective. If $F_{\text {Calculated }}<F_{\text {Table }}$, then decision is ineffective.

Statistical models to predict the surface area can be built up using the Yates data analysis (Table 5). These models can be used to analyze the residues and check the assumption about the experimental error distribution of the factorial designs [11]. The regression equation with interactive terms can be written as follows:

$$
\begin{gathered}
Y=b_{0}+b_{1} X_{1}+b_{2} X_{2}+b_{3} X_{1} X_{2}+b_{4} X_{3}+b_{5} X_{1} X_{3}+b_{6} X_{2} X_{3}+b_{7} X_{1} X_{2} X_{3}+b_{8} X_{4}+b_{9} X_{1} X_{4}+b_{10} X_{2} X_{4}+ \\
b_{11} X_{1} X_{2} X_{4}+b_{12} X_{3} X_{4}+b_{13} X_{1} X_{3} X_{4}+b_{14} X_{2} X_{3} X_{4}+b_{15} X_{1} X_{2} X_{3} X_{4}
\end{gathered}
$$


where $Y=$ response (surface area $\left.\left(\mathrm{m}^{2} / \mathrm{cm}^{3}\right)\right), X_{1}=$ grinding time $(\mathrm{min}), X_{2}=$ stirrer speed $(\mathrm{rpm}), X_{3}=$ powder filling ratio $(f c)$ and $X_{4}=$ ball filling ratio. The models formed for surface area of talc using the effects of variable significant at either $95 \%$ or more confidence level are given below:

$$
\begin{aligned}
& Y=2.472+0.271 X_{1}+0.112 X_{2}+0.051 X_{1} X_{2}-0.156 X_{3}-0.059 X_{1} X_{3}-0.033 X_{2} X_{3}+0.117 X_{4}+ \\
& 0.036 X_{1} X_{4}+0.019 X_{2} X_{4} .
\end{aligned}
$$

The coefficient of determination, $R^{2}$, was used to check the models ability to predict the response of active ratio accurately. It is determined from the following equation:

$$
R^{2}=1-\left[\left\{\sum\left(y_{i}-y_{i}\right)^{2}\left\{\sum\left(y_{i}-y_{i}^{-}\right)^{2}\right\}\right]\right.
$$

where $y^{\wedge}$ is the predicted response variable and $y$ - is the mean experimental value. If $R^{2}$ is 1 , then the prediction is nearly perfect. However, if $R^{2}$ becomes zero, the model has little value. The empirical models were found to accurately estimate the response variable as indicated by $R^{2}$ value $(0.9989$ for $S_{v}$ ). The residual analyses for volumetric surface area are presented in Fig. 3.

The main effects of each variable on the volumetric surface area $\left(\mathrm{m}^{2} / \mathrm{cm}^{3}\right)$ that are significant at the $95 \%(a<0.05)$ confidence level are presented in Fig. 4 . The order of significance is $a>c>d>b$. The most dominant effect is $a$ (grinding time) and its effect is positive. The effect of powder filling ratio $(c)$ is the second most significant and it has a negative effect. The stirrer speed $(b)$ and ball filling ratio (d) have also a positive effect. The $a b, a d$ and $b d$ interactions have positive effects, whereas that of $a c$ and $b c$ has a negative effect on the surface area of the ground product of grinding of talc. Figure 5 and Table 5 also show the comparison of $a, b, c, d, a b d$ and feed.

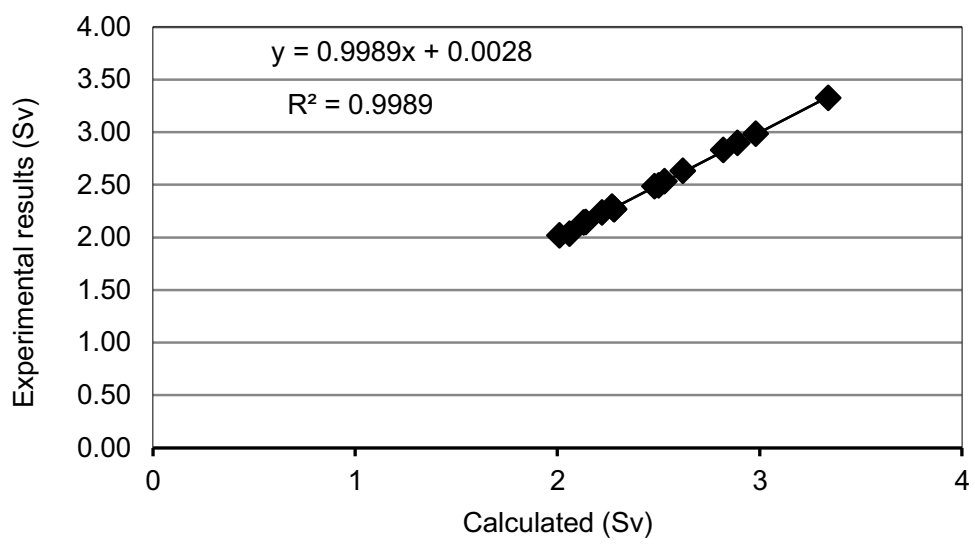

Figure 3. Residual analyses for volumetric surface area $\left(S_{v}\right)$.

Table 5. Comparison of the results for some products.

\begin{tabular}{lcccc}
\hline & $\boldsymbol{S}_{\boldsymbol{v}}\left(\mathbf{m}^{\mathbf{2}} / \mathbf{c m}^{\mathbf{3}}\right)$ & $\boldsymbol{d}_{\mathbf{1 0}}(\boldsymbol{\mu} \mathbf{m})$ & $\boldsymbol{d}_{\mathbf{5 0}}(\boldsymbol{\mu} \mathbf{m})$ & $\boldsymbol{d}_{\mathbf{9 0}}(\boldsymbol{\mu} \mathbf{m})$ \\
\hline Feed & 1.57 & 1.54 & 6.26 & 69.33 \\
$a$ & 2.62 & 0.99 & 3.18 & 14.38 \\
$b$ & 2.27 & 1.13 & 3.84 & 17.82 \\
$c$ & 2.01 & 1.28 & 4.43 & 26.61 \\
$d$ & 2.28 & 1.09 & 3.84 & 27.02 \\
$a b d$ & 3.34 & 0.82 & 2.33 & 7.09 \\
\hline
\end{tabular}




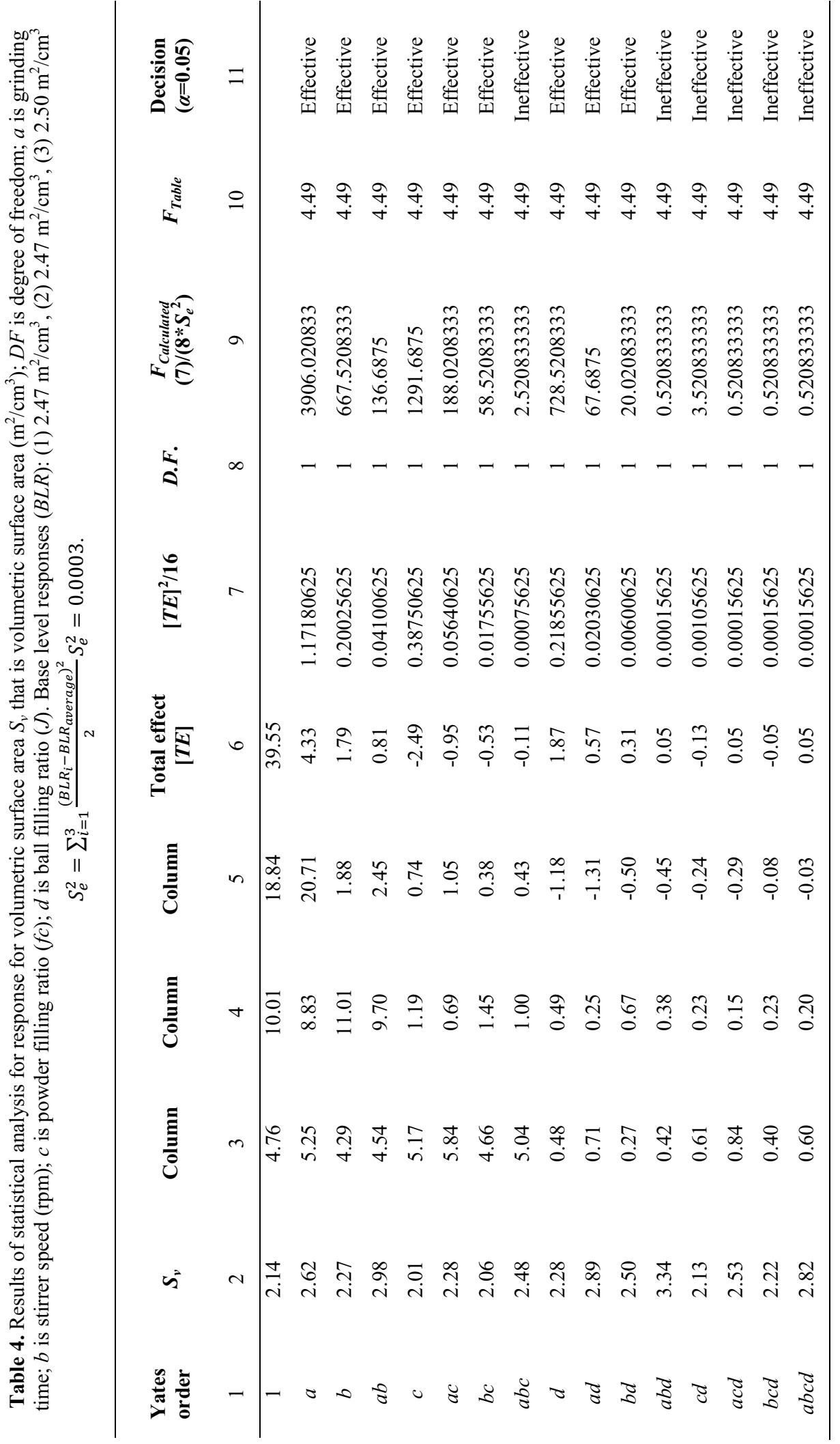




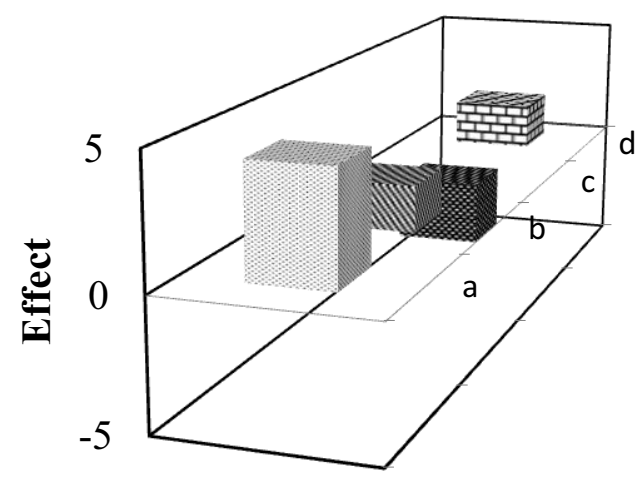

Figure 4. The main effects of each variable on the volumetric surface area $\left(\mathrm{m}^{2} / \mathrm{cm}^{3}\right): a=$ grinding time (min), $b=$ stirrer speed (rpm), $c=$ the powder filling ratio $(f c)$ and $d=$ ball filling ratio.

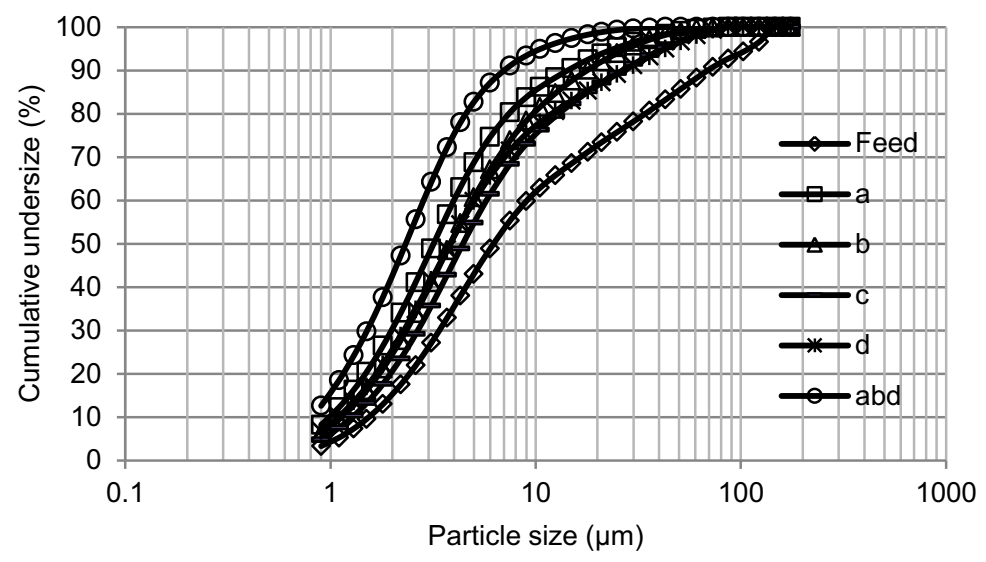

Figure 5. Particle size distributions of some products ( $a b d$ : finest product).

\section{Conclusions}

As a result of statistically designed experiments performed, the optimum grinding conditions of talc (as a volumetric surface area of product obtained) in a stirred ball mill was determined to be; grinding time $15 \mathrm{~min}$, stirrer speed of $600 \mathrm{rpm}$, powder filling ratio of $0.03(f \mathrm{c})$, ball filling ratio of $0.70(J)$. The most dominant and positive effect was the grinding time The effect of powder filling ratio was the second most significant and it had a negative effect. The stirrer speed and ball filling ratio $(J)$ had also a positive effect. The volumetric surface area $\left(S_{v}\right)$ by dry grinding using stirred ball mill was increased in comparison to the feed. The correlation coefficient of the model estimated at $95 \%$ confidence level with effective factors had a high value of 0.9989 .

\section{Acknowledgments}

The author would like to thank MİCRON' S Company (Nigde, Turkey) for providing samples. 


\section{References}

1. Mondo Minerals, www.mondominerals.com, (2016)

2. R. Sivamohan, P. Vachot, Powder Technol., 61, 119 (1990)

3. O. A. Orumwense, and E. Forssberg, Scand. J. Merall., 19, 201 (1990)

4. R. F. Conley, in G. Malghan (ed.), 112th AZME Meeting. Atlanta, GA, AIME, 37, (1983)

5. N. Stehr, R. K. Mehta and J. A. Herbst, Coal Prep., 4, 209, (1987)

6. E. G. Davis, J. P. Hansen and G. V. Sullivan, in P. Somasundaran (ed.), SME, 74, (1980)

7. O. Y. Toraman, Part. Sci. Technol., 31, 205, (2013)

8. Yates, F., Design and analysis of a factorial experiment (UK: Imperial Bureau of Soil Science, 1976).

9. G. Özbayoğlu, M. Atalay, J. Alloy. Comp., 303-304, 520 (2000)

10. E. Yoğurtcuoğlu, M. Uçurum, Powder Technol., 214, 47 (2011)

11. D. C. Montgomery, Design and analysis of experiments (Arizona State University, 1981) 